\title{
PENGARUH KEAKTIFAN SISWA DAN KOMUNIKASI MATEMATIS TERHADAP PRESTASI BELAJAR MATEMATIKA SISWA
}

\author{
Faridatus Solicha dan Ilma Dwi Cahyanti \\ Jurusan Tadris Matematika, Institut Agama Islam Negeri (IAIN) Tulungagung \\ Jl. Mayor Sujadi Timur No. 46 Tulungagung \\ e-mail: faridatussolicha39@gmail.com
}

\begin{abstract}
Abstrak
Keaktifan siswa saat belajar di kelas, baik keaktifan mencatat, bertanya serta menjawab, dan juga mempresentasikan hasil yang telah diperoleh dalam mengerjakan soal yang diberikan guru serta kemampuan komunikasi matematika yang baik akan mempengaruhi nilai atau prestasi matematika setiap anak. Kenyataannya di dalam kelas masih terdapat siswa yang masih dibawah standart kategori aktif. Sedangkan pada komunikasi matematika dilihat dari hasil tes mengerjakan soal yang diberikan oleh peneliti. Pada penelitian ini metode penelitan yang digunakan adalah metode penelitian kuantitatif dengan menggunakan uji regresi dan uji korelasi. Pada penelitian ini teknik pengambilan sampelnya secara acak (random) dan sampel yang sebanyak 19 siswa. Hasil penelitian yang didapat menunjukkan: (1) Terdapat pengaruh yang signifikan keaktifan siswa terhadap prestasi belajar matematika. Dari ringkasan tabel ANOVA terlihat bahwa untuk taraf signifikansi sebesar 5\% atau 0,05 diperoleh sig $=0,000<0,05$. Dengan demikian, H0 ditolak dan $\mathrm{H} 1$ diterima, artinya terdapat pengaruh yang signifikan keaktifan siswa terhadap prestasi belajar matematika.(2) Terdapat pengaruh yang signifikan komunikasi matematika terhadap prestasi belajar matematika.Dari ringkasan tabel ANOVA terlihat bahwa untuk taraf signifikansi sebesar $5 \%$ atau 0,05 diperoleh sig $=0,005<0,05$. Dengan demikian, H0 ditolak dan $\mathrm{H} 1$ diterima, artinya terdapat pengaruh yang signifikan komunikasi matematis terhadap prestasi belajar matematika.(3)Terdapat pengaruh yang signifikan keaktifan siswa dan komunikasi matematis terhadap prestasi belajar matematika.Dari ringkasan tabel SUMMARY terlihat bahwa untuk taraf signifikansi sebesar 5\% atau 0,05 diperoleh sig $=0,000<0,05$. Dengan demikian, H0 ditolak dan H1 diterima, artinya terdapat pengaruh yang signifikan keaktifan siswadan komunikasi matematis terhadap prestasi belajar matematika. Jadi dapat disimpulkan bawa terdapat pengaruh keaktifan siswa dan komunikasi matematika terhdap prestasi belajar matematika. Dan saran dari peneliti bagi guru adalah hendaknya memancing siswanya untuk aktif saat pembelajaran dikelas dilaksanakan, dan juga lebih membiasakan siswa untuk berkomunikasi secara matematis, khsususnya pada pelajaran matematika.
\end{abstract}

Kata Kunci: keaktifan siswa, komunikasi matematis, prestasi belajar matematika.

\begin{abstract}
s
Activity of students while studying in the classroom, both liveliness notes, ask and answer, and also presented the results that have been obtained in working on the teacher as well as good communication skills math will affect the value or the mathematical achievement of every child. The reality in the classroom there are students who are still active under the
\end{abstract}


standard category. While the mathematics communication seen from the test results to the problems given by the researchers. In this study the research method used is quantitative method by using regression and correlation. In this study, a random sampling technique (random) and sample as many as 19 students. Research results obtained show: (1) There is a significant influence on the activity of the student mathematics achievement. From the ANOVA summary table is seen that for a significance level of $5 \%$ or 0.05 obtained sig $=$ $0.000<0.05$. Thus, $\mathrm{H} 0$ is rejected and $\mathrm{H} 1$ accepted, meaning that there is significant influence activity of students towards mathematics achievement. (2) There is a significant effect on the learning achievement of mathematics communication matematika.Dari ANOVA summary table is seen that for a significance level of $5 \%$ or 0,05 obtained sig $=$ $0.005<0.05$. Thus, $\mathrm{H} 0$ is rejected and $\mathrm{H} 1$ accepted, meaning a significant influence to the mathematical communication mathematics achievement. (3) There is a significant effect of active students and mathematical communication to mathematics achievement. From the summary table SUMMARY seen that for a significance level of $5 \%$ or 0.05 obtained sig $=$ $0.000<0.05$. Thus, $\mathrm{H} 0$ is rejected and $\mathrm{H} 1$ accepted, meaning a significant influence on the activity of mathematical communication siswadan mathematics achievement. So we can conclude there are significant take active students and mathematics communication terhdap mathematics achievement. And advice from researchers for teachers is should provoke students to active learning time in class conducted, and also familiarize students to communicate mathematically up, especially in math. meaning that there is a significant effect on the activity of mathematical communication siswadan mathematics achievement. So we can conclude there are significant take active students and mathematics communication terhdap mathematics achievement. And advice from researchers for teachers is should provoke students to active learning time in class conducted, and also familiarize students to communicate mathematically up, especially in math. meaning that there is a significant effect on the activity of mathematical communication siswadan mathematics achievement. So we can conclude there are significant take active students and mathematics communication terhdap mathematics achievement. And advice from researchers for teachers is should provoke students to active learning time in class conducted, and also familiarize students to communicate mathematically up, especially in math.

Keywords: student activity, mathematical communication, mathematics achievement.

\section{PENDAHULUAN}

Pendidikan mempunyai peran yang sangat penting dalam meningkat mutu dan kualitas sumber daya manusia dan upaya dalam mewujudkan cita-cita bangsa Indonesia dalam mewujudkan kesejahteraan umum dan mencerdaskan kehidupan bangsa.Dalam meninngkatkan sumber daya manusia melalui pendidikan perlu mendapatkan perhatian khusus. Undang-undang Pendidikan No. 20
Tahun 2003 Tentang Sistem Pendidikan Nasional yang berfungsi mengembangkan kemampuan membentuk watak dan peradaban bangsa yang bermartabat dalam rangka mencerdaskan kehidupan bangsa bertujuan untuk mengembangkan potensi peserta didik agar menjadi manusia yang beriman dan bertaqwa kepada Tuhan Yang Maha Esa berakal mulia, sehat, berilmu, cakap kreatif, mandiri, dan 
menjadi warga negara yang demokratis dan peduli terhadap perkembangan zaman (Muhardi, 2004: 480).

Kegiatan belajar merupakan proses di sekolah. Ini artinya berhasil tidaknya suatu pendidikan seorang siswa tergantung pada pencapaian taksonomi pendidikan yang dialami siswa yang mencakup aspek kognitif dan aspek psikomotorik (Siagian, 2013: 123).Keberhasilan siswa dalam belajar dapat dipengaruhi oleh keaktifan yang dimiliki pada saat pembelajaran di kelas.Selain keaktifan juga dapat dilihat bagaimana komunikasi matematis yang dimiliki oleh siswa tersebut.Seperti pada pembelajaran matematika. Dalam belajar matematika kita tidak hanya cukup melihat guru menjelaskan saja, serta mencacat apa yang ditulis pada papan tulis. Namun siswa juga harus aktif dalam bertanya dan mengemukakan pendapatnya, karena dengan begitu kita akan lebih memahami lagi materi yang sudah djelaskan.

Seorang siswa dikatakan belajar dengan aktif jika mereka mendominasikan aktivitas pembelajaran. Siswa secara aktif menggunakan otak, baik untuk menemukan ide pokok dari materi, memecahkan persoalan, atau mengaplikaskan apa yang dipelajari (Kurniasari, 2013: 3). Aktivitas dalam suatu pembelajaran bukan hanya aktif belajar saja tetapi dilain pihak, guru juga harus mengorganisasi suatu kondisi yang dapat mengaktifkan siswa dalam belajar (Kusdiana dkk, 2011: 3). Bukan hanya dikatakan aktif dalam pembelajaran juga, siswa dikatakan berhasil dalam belajar jika dia mampu menyampaikan kembali apa yang sudah ia dapat dan ia pahami kepada orang lain. Yaitu mengkomunikasikan apa yang telah ia dapatkan.

Khususnya dalam pembelajaran matematika, komunikasi yang sedemikian sangatlah diperlukan guna untuk mengetahui seberapa paham siswa tersebut terhadap materi yang sudah diajarkan oleh guru.Komunikasi dalam pembelajaran mamatika sering kali kita sebut dengan komunikasi matematis. Untuk mengetahui komunikasi matematis siswa, terdapat dua pilihan, yaitu dengan melihat bagaimana siswa tersebut menyampaikan apa yang sudah ia dapatkan kemudian ia presentasikan di depan teman-temannya dan guru (Purnama \& Ekasatya, 2016: 3). Dan yang kedua adalah dengan lembar pengerjaan soal latihan yang sudah dikerjakan oleh siswa. Jika siswa mengerjakan latihan soal, dan lembar jawabannya berisikan jawaban yang benar dan runtut, serta siswa menampilakan segala sesuatu ide yang ia miliki, maka dapat dikatakan bahwa 
siswa itu juga memiliki kemampuan komunikasi matematis yang baik. Siswa dengan keaktifan dan komunikasi matematis yang baik, maka pretasi belajar matematika juga baik.

Namun pada kenyataannya banyak siswa yang masih menjadi penonton saja pada saat pembelajaran matematika dilaksanakan dalam kelas.Siswa cenderung hanya diam dan kurang aktif dalam pembelajaran matematika (Zakiya,dkk, 2016: 4).Di samping itu siswa juga cenderung malas saat mengerjakan tugas yang diberikan oleh guru. Ketika siswa ditanya oleh guru “apakah sudah paham?”, mereka menjawab "paham". Namun pada kenyatannya dilapangan, siswa ketika disuruh mengerjakan di depan kelas dan menjelaskan kepada temannya, mereka masih belum bisa. Maka dapat di ambil kesimpulan bahwa ternyata prestasi belajar matematika tidak bisa rata di dalam satu kelas dikarenakan kurangnya keaktifan siswa di dalam kelas, disamping itu juga kurangnya keterampilan komunikasi matematis siswa, sehingga guru seharusnya lebih sering mengajari siswa agar terbiasa untuk lebih mematangkan kemampuan siswa dalam pendalam materi, dan juga melatih siswa agar dapat menyampaikan apa yang sudah mereka dapatkan pada pembelajaran tersebut.
Pentingnya penelitian bertujuan agar guru lebih memancing siswa agar aktif di dalam kelas, bukan hanya monoton diam dan menyaksikan apa yang disampaikan oleh guru, namun siswa juga dipancing agar ikut bicara dalam maksud bertanya, menjawab (jika guru memberikan umpan tanya balik), dan juga mempresentasikan di depan kelas hasil pekerjaannya (Marwodo, 2014: 26).

\section{TINJAUAN PUSTAKA}

\section{Keaktifan Siswa}

Keaktifan siswa dalam belajar merupakan persoalan penting dan mendasar yang harus dipahami, didasari dan dikembangkan oleh setiap guru dalam proses pembelajaran. Keaktifan belajar ditanda adanya keterlibatan secara optimal, baik intelektual emosi dan fisik.Siswa merupakn manusia belajar yang aktif dan ingin tahu. Daya keaktifan yang dimiliki anak secara kodrati itu akan dapat berkembang ke arah yang positif saat lingkungannya memberikan ruang yang baik untuk perkembanga keaktifan itu (dalam Imenda, 2017: 3) .

Keaktifan siswa dalam belajar menurut Rousseau dalam Sardiman. AM (dalam Rahmawati, 2012: 3) bahwa keaktifan adalah segala pengtahuan yag diperoleh dengan pengamatan sendiri, bekerja sendiri, dengan fasilitas yang 
diciptakan sendiri bak secara rohani maupun teknis. Hal tersebut dimaksudkan bahwa keaktifan siswa dalam belajar sangatlah diperlukan adanya aktivitas tanpa adanya aktifitas, belajar tidak akan berlangsung dengan baik. Jadi dalam belajar seseorang yang belajar haruslah aktif sendiri karena tanpa adanya aktivitas yang terjadi dalam belajar maka proses belajar tidak akan terjadi.

Dalam kegiatan pembelajaran di kelas, siswa diharapkan dapat meningkatkan keaktifan yang diukur dari indikator: a) menjawab pertanyaan, b) mengajukan pertanyaan, ide atau tanggapan, c) mengerjakan tugas dan berani maju di depan kelas, d)menyanggah atau menyetujui ide sisiwa yang lain. Dengan adanya keaktifan pada setiap siswa, maka akan membantu dalam pencapaian tujuan. Sedangkan indikator hasil belajar dapat dilihat dari pencapaian terhadap krteria ketuntasan minimal atau yang sering kita kenal dengan KKM (dalam Crisna dan Sumardi, 2013: 3)

\section{Komunikasi Matematis}

Komunikasi

matematis

merupakan (dalam Agustyaningrum, 2011: 377) suatu cara siswa untuk mengungkapkan ide-ide matematis baik secara lisan, tertulis, gambar, diagram, menggunakan benda, menyajikan dalam bentuk aljabar, atau menggunakan simbol matematika. Siswa yang mendengarkan dalam pembelajaran matematika mendapatkan dua hal sekaligus, yaitu komunikasi untuk mempelajari matematika (communicate to learn mathematics) dan belajar untuk berkomunikasi secara matematis (learn to communicate mathematically). Dalam (Depdiknas, 2004: 24) juga disebutkan bahwa komunikasi matematis merupakan kesanggupan atau kecakapan siswa untuk menyatakan dan menafsirkan gagasan matematis secara lisan, tertulis, atau mendemonstrasikan apa yang ada dalam persoalan matematika.

Berdasarkan Principles and Standards for School Mathematics dari NCTM tahun $2000 \quad$ (dalam Agustyaningrum, 2011: 378)kemampuan komunikasi matematis siswa dapat dlihat dari beberapa aspek sebagai berikut:

Kemampuan menyatakan ide-ide matematis melalui lisan, tulisan, serta menggambarkan secara visual. Kemampuan ini menekankan pada kemampuan siswa menjelaskan, menulis, maupun membuat sketsa atau gambar tentang ide-ide matemat yang dimiliki untuk menyelesaikan masalah. pemahaman terhadap suatu ide karena dapat memperluas interprestasi nyata dari suatu soal. 
Kemampuan siswa dalam menggunakan istilah, simbol matematika, dan struktur-strukturnya untuk memodelkan situasi atau permasalahan matematika. Menurut Widiarti dan Pamuntjak (dalam Agustyaningrum, 2011: 379) pemodelan matematis adalah suatu cara untuk mendeskripsikan beberapa fenomena kehidupan nyata dalam istilah matematika (secara matematika). Dari pendapat beberapa ahli yang telah dikemukakan di atas, peneliti menyimpulkan bahwa kemampuan komunikasi matematis siswa dapat ditinjau dari cara komunikasi lisan dan tulisan.

\section{Pretasi Belajar Matematika}

Belajar adalah suatu proses kompleks yang terjadi pada semua orang yang berlangsung seumur hidup. Karena kompleksnya masalah belajar banyak sekali teori yang menjelaskan bagaimana proses belajar itu terjadi. Menurut Hamalik (dalam Siagian, 2013: 124) "belajar adalah modifikasi atau memperteguh kelakuan melalui pengalaman (learning is defined as the modification or strengthening of behavior through experiencing)". Dengan kata lain belajar merupakan perubahan yang terjadi pada diri individu sebagai hasil dari pengalaman itu sebenarnya usaha dari individu sendiri dalam interaksi dengan lingkungannya. Interaksi yang dimaksud tidak lain adalah interaksi edukatif yang memungkinkan terjadinya interaksi proses belajar mengajar. Dipertegas Abdurrahman dan Mulyono "belajar adalah suatu bentuk pertumbuhan atau perubahan dalam diri seseorang yang dinyatakan dalam caracara bertingkah laku yang baru berkat pengalaman dan latihan". Terjadinya perubahan dalam situasi tertentu seiring isi ingatan yang membuat belajar itu senantiasa merupakan perubahan tingkah laku atau penampilan, dengan serangkaian kegiatan misalnya dengan membaca, mengamati, mendengarkan, meniru dan sebagainya. Sesuai dengan Irwanto dikatakan "belajar secara sederhana sebagai proses perubahan dari belum mampu menjadi sudah mampu (yang), terjadi dalam jangka waktu tertentu. Perubahan yang terjadi itu harus secara relatif bersifat menetap (permanen) dan tidak hanya terjadi pada prilaku yang saat ini nampak (immediate behavior) tetapi juga pada perilaku yang mungkin terjadi dimasa mendatang (potensial behavior)" (dalam Siagian, 2013: 124).

Prestasi belajar yang dicapai seseorang merupakan hasil interaksi antar lingkungan,keluarga dan masyarakat sesuai pendapat 
Ahmadi(dalam Siagian, 2013: 124) prestasi belajar yang dicapai seseorang merupakan hasil interaksi berbagai faktor yang mempengaruhinya baik dari dalam diri (faktor internal) maupun dari luar diri (faktor eksternal) individu. Pengenalan terhadap faktor-faktor yang mempengaruhi prestasi belajar penting sekali artinya dalam rangka membantu murid dalam mencapai prestasi belajar yang sebaik-baiknya. Menurut Cronbach (dalam Siagian, 2013: 124) mengatakan bahwa: Kegunaan prestasi belajar banyak ragamnya, antara lain sebagai umpan balik bagi guru dalam mengajar, untuk keperluan diagnostic, untuk keperluan bimbingan dan penyuluhan, untuk keperluan seleksi, untuk keperluan penempatan atau penjurusan, untuk menentukan isi kurikulum, dan untuk menentukan kebijakan sekolah.

Prestasi belajar matematika pada dasarnya adalah hasil akhir yang diharapkan dapat dicapai setelah seseorang belajar. Menurut Ahmad Tafsir(dalam Nastitie, 2011: 11-12), prestasi belajar matematika yang diharapkan itu merupakan suatu target atau tujuan pembelajaran yang meliputi indikator:1) tahu, mengetahui (knowling); 2) terampil melaksanakan atau mengerjakan yang ia ketahui itu (doing); dan 3) melaksanakan yang ia ketahui itu secara rutin dan konsekwen (being).

\section{METODE PENELITIAN}

Metode penelitan menggunakan metode penelitian kuantitatif. Metode penelitian kuantitatif adalah metode penelitan yang berlandaskan pada filsafat positivisme (dalam Sugiyono, 2017: 14). Penelitian diadakan pada SMP Mamba'unuur Bululawang Kota Malang dikarenakan letak yang strategis dan mudah dijangkau oleh peneliti dan sampel sesuai dengan kategori untuk diteliti. Populasi penelitian adalah siswasiswi SMP Mamba'unnur Bululawang kelas VIII pada tahun ajaran 2017/2018, penentuan sampel dilakukan dengan tekniksimple random sampling, yaitu peneliti mengambil sampel secara random atau acak, sampel yang diambil adalah kelas VIII-C dengan jumlah siswa sebnayak 19 anak.

Data penelitian diantaranya adalah dengan mengumpulkan hasil tes soal yang diberikan oleh peneliti dan juga data dokumentasi yang dimiliki oleh wali kelas. Instrumen yang digunakan untuk menggali data berupa tes dan dokumentasi dan untuk lainnya dengan cara peneliti sebagai observer didalam kelas. Soal tes yang diberikan kepada siswa berupa soal uraian sebanyak 5 soal. Dalam instrumen ini bertujuan untuk 
menguji kemampuan matematis siswa pada pembelajran matematika. Sebelum instrumen diujikan kepada siswa, maja hendak di uji validitas dan uji reliabilitas. Dari hasil uji validitas butir tes soal menggunakan indeks validitasnya lebih dari atau sama dengan 0,30 agar dapat dikakatan bahwa soal tersebut valid (Sugiyono, 2017: 179).

Pada pengujian hasil penelitian menggunakan uji korelasi dan uji regresi. Sebelum menggunakan uji korelasi dan juga uji regresi, perhitungan awal adalah dengan menguji data terlebih dahulu, yaitu dengan uji normalitas. Pada perhitugan uji normalitas dengan $C h i$ Square dengan menggunakan alat bantu SPSS 22 for Windowsdidapatkan bahwa data berdistribusi normal, maka pengujian hipotesis dilakukan dengan statistika parametrik.Untuk mempermudah memahami konsep penelitian ini, maka diharapkan rancangan desain penelitan ini dapat memberikan gambaran yang jelas.

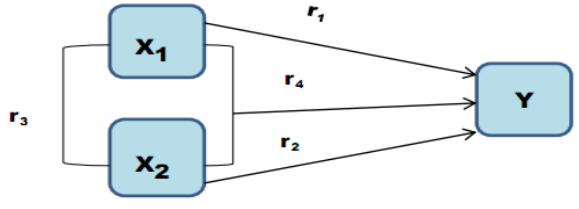

Gambar 1. Desain Penelitian

Keterangan :

$\mathrm{X}_{1}$ : Keaktifan Siswa

$\mathrm{X}_{2}$ : Komunikasi Matematis

Y : Prestasi Belajar Matematika

\section{HASIL DAN PEMBAHASAN}

Dari hasil penelitian yang di dapat dengan memberi soal tes kepada siswa, observasi di dalam kelas, serta dokumentasi data nilai yang dimiliki oleh guru, maka data diuji dengan uji normalitas terlebih dahulu.Dengan data variabel yang dideskripsikan adalah data variabel bebas Keaktifan $\left(\mathrm{X}_{1}\right)$ dan Komunikasi Matematis $\left(\mathrm{X}_{2}\right)$, dengan variabel terikatnya adalah Prestasi Belajar Matematika (Y).

\section{Pengujian Persyaratan Data}

Data yang telah dikumpulkan selanjutkan diuji persyaratan analisis, yang meliputi uji normalitas.Data harus diuji normalitas terlebih dahulu, jika data berdistribusi normal maka dilanjutkan dengan menggunakan uji statistika parametrik, yaitu uji korelasi dan uji regresi. Untuk hasil uji normalitas dengan perhitungan SPSS 22 for Windows sebagai berikut:

a. Keaktifan

Terlihat angka Chi Square hitung adalah5,737. Sehingga untuk df $=9$ dengan taraf signifikasi 0,05diperoleh Chi Square tabel $=16,919$. Maka diperoleh $5,737<16,919$. Karena $\mathrm{X}_{\text {hitung }^{2}}<\mathrm{X}_{\text {tabel }^{2}}$, maka distribusi data Keaktifan (X1) tersebut normal. Maka dapat dikatakan bahwa H0 ditolak.

b. Komunikasi 
Terlihat angka Chi Square hitung adalah9,368. Sehingga untuk df $=6$ dengan taraf signifikasi 0,05diperoleh Chi Square tabel $=15,507$. Maka diperoleh 9,368 $<12,592$. Karena $\mathrm{X}_{\text {hitung }^{2}}<\mathrm{X}_{\text {tabel }^{2}}$, maka distribusi data Keaktifan (X2) tersebut normal. Maka dapat dikatakan bahwa H0 ditolak.

c. Prestasi

Terlihat angka Chi Square hitung adalah4,158 Sehingga untuk df $=7$ dengan taraf signifikasi 0,05diperoleh Chi Square tabel $=15,507 . \quad$ Maka diperoleh 4,158< 14,067. Karena $\mathrm{X}_{\text {hitung }^{2}}<\mathrm{X}_{\text {tabel }^{2}}$, maka distribusi data Keaktifan (Y) tersebut normal. Maka dapat dikatakan bahwa $\mathrm{H} 0$ ditolak.
Dari hasil uji normalitas a, b, dan c maka disimpulkan data berdistribusi normal, maka dapat dilanjutkan dengan uji statistik parametrik, yaitu uji korelasi

\section{Pengujian Hipotesis Penelitian}

\section{Terdapat pengaruh keaktifan siswa terhadap prestasi belajar matematika}

Menggunakan uji korelasi variabel Keaktifan Siswa $\left(X_{1}\right)$ terhadap variable Prestasi Belajar matematika (Y) untuk mengetahui tingkat eratan hubungan kedua variabel dalam penelitian ini menggunakan uji regresi sederhana pada SPSS 22 for windows. Dari perhitungan didapatkan SPSS dapat dipaparkan Tabel 1 berikut:

Tabel 1. Model Summary

\begin{tabular}{|c|c|c|c|c|}
\hline Model & $\mathrm{R}$ & R Square & $\begin{array}{c}\text { Adjusted R } \\
\text { Square }\end{array}$ & $\begin{array}{c}\text { Std. Error of } \\
\text { the Estimate }\end{array}$ \\
\hline 1 &, $797^{\mathrm{a}}$ &, 636 &, 614 & 9,87907 \\
\hline
\end{tabular}

a. Predictors: (Constant), prestasi

Dari Tabel 1 diatas diketahui bahwa nilai korelasi $(\mathrm{R})$ yairu 0,797 dan besar koefisien determinasi (R2) sebesar 0,636. Yang mengandung pengaruh

Untuk hasil output bagian kedua

Tabel 2. Hasil Uji ANOVA ${ }^{\mathrm{a}}$

\begin{tabular}{|ll|l|l|l|l|l|}
\hline \multicolumn{1}{|c|}{ Model } & \multicolumn{1}{|c|}{$\begin{array}{c}\text { Sum of } \\
\text { Squares }\end{array}$} & df & Mean Square & F & \multicolumn{1}{c|}{ Sig. } \\
\hline 1 & Regression & 2892,676 & 1 & 2892,676 & 29,639 &, $000^{\mathrm{b}}$ \\
& Residual & 1659,133 & 17 & 97,596 & & \\
& Total & 4551,809 & 18 & & & \\
\hline
\end{tabular}

variabel bebas terhadap variabel terikat adalah 63,6\%, sedangkan sisanya dipengaruhi oleh variabel lainnya. 
a. Dependent Variable: keaktifan

b. Predictors: (Constant), prestasi

Dari hasil output Tabel 2 diatas dapat dilihat bahwa $\mathrm{F}$ hitung $=29,639$ dengan tingkat signifikansi $0,000<0,05$ Untuk hasil output bagian ketiga

Tabel 3. Coefficients ${ }^{\mathrm{a}}$

\begin{tabular}{|cc|c|c|l|c|c|}
\hline & & \multicolumn{2}{|c|}{$\begin{array}{c}\text { Unstandardized } \\
\text { Coefficients }\end{array}$} & $\begin{array}{c}\text { Standardized } \\
\text { Coefficients }\end{array}$ & & \\
\cline { 3 - 5 } & Model & B & Std. Error & Beta & T & Sig. \\
\hline 1 & (Constant) & $-6,496$ & 13,827 & &,- 470 &, 644 \\
& Prestasi &, 980 &, 180 &, 797 & 5,444 &, 000 \\
\hline
\end{tabular}

a. Dependent Variable: keaktifan

Dari Tabel 3 diatas, pada kolom B pada constant (a) adalah -6,496, sedangkan nilai Prestasi (b) adalah 0,980 sehungga persemaan regresinya adalah : $Y=-6,496+0,980 X$.

Untuk uji signifikasi variabel keaktifan $\mathrm{X}_{1}$ terhadap variabel prestasi belajar matematika (Y) dapat dilihat dari nilai $\mathrm{t}$ hitung $=$ dengan signifikasi 0,000 $<$ 0,05 . maka H0 di tolak, dan H1 diterima, yang berarti ada hubungan yang signifikan keaktifan siswa terhadap prestasi belajar matematika, dan penelitian ini berlaku untuk umum tidak hanya untuk sampel yang diteliti saja. maka model regresi dapat dipakai untuk memprediksi variabel bebas. 
Dari Tabel 4, diketahui bahwa nilai korelasi $(\mathrm{R})$ yairu 0,613 dan besar koefisien determinasi (R2) sebesar 0,376. Yang mengandung pengaruh variabel bebas terhadap variabel terikat adalah $37,6 \%$, sedangkan sisanya dipengaruhi oleh variabel lainnya.

Untuk hasil output bagian kedua

Tabel 5. Hasil Uji ANOVA ${ }^{\mathrm{a}}$

\begin{tabular}{|c|c|c|c|c|c|c|}
\hline \multicolumn{2}{|c|}{ Model } & $\begin{array}{l}\text { Sum of } \\
\text { Squares }\end{array}$ & $\mathrm{df}$ & Mean Square & $\mathrm{F}$ & Sig. \\
\hline \multirow[t]{3}{*}{1} & Regression & 551,827 & 1 & 551,827 & 10,235 &, $005^{\mathrm{b}}$ \\
\hline & Residual & 916,594 & 17 & 53,917 & & \\
\hline & Total & 1468,421 & 18 & & & \\
\hline
\end{tabular}

a. Dependent Variable: komunikasi

b. Predictors: (Constant), prestasi

Dari hasil output diatas dapat dilihat bahwa $\mathrm{F}$ hitung $=10,235$ dengan tingkat signifikansi $0,005<0,05$ maka model regresi dapat dipakai untuk memprediksi variabel terikat.

Tabel 6. Coefficients ${ }^{\mathrm{a}}$

\begin{tabular}{|c|c|c|c|c|c|c|}
\hline \multirow{2}{*}{\multicolumn{2}{|c|}{ Model }} & \multicolumn{2}{|c|}{$\begin{array}{c}\text { Unstandardized } \\
\text { Coefficients }\end{array}$} & \multirow{2}{*}{$\begin{array}{c}\text { Standardized } \\
\text { Coefficients } \\
\text { Beta }\end{array}$} & \multirow[b]{2}{*}{1} & \multirow[b]{2}{*}{ Sig. } \\
\hline & & B & Std. Error & & & \\
\hline \multirow[t]{2}{*}{1} & (Constant) & 39,934 & 10,277 & & 3,886 & ,001 \\
\hline & Prestasi & ,428 & 134 & ,613 & 3,199 & ,005 \\
\hline
\end{tabular}

a. Dependent Variable: komunikasi

Dari hasil output tabel 6 diatas, pada kolom B pada constant (a) adalah 39,934, sedangkan nilai Pretasi (b) adalah 0,428 sehungga persemaan regresinya adalah : $Y=39,934+0,428 X$.

Untuk uji signifikasi variabel komunikasi matematis $\mathrm{X}_{2}$ terhadap variabel prestasi belajar matematika (Y) dapat dilihat dari nilai t hitung $=$ dengan signifikasi $0,005<0,05$. maka H0 di tolak, dan H1 diterima, yang berarti ada hubungan yang signifikan komunikasi matematis terhadap prestasi belajar matematika, dan penelitian ini berlaku untuk umum tidak hanya untuk sampel yang diteliti saja. 


\section{Terdapat pengaruh keaktifan siswa dan komunikasi matematis terhadap prestasi belajar matematika}

Menggunakan uji regresi variabel Keaktifan Siswa $\left(\mathrm{X}_{1}\right)$ dan Komunikasi Matematis $\left(\mathrm{X}_{2}\right)$ terhadap variable Prestasi Belajar matematika (Y) untuk mengetahui tingkat eratan hubungan ketiga variabel dalam penelitian ini menggunakan uji korelasi ganda pada SPSS 22 for windows. Dari perhitungan didapatkan SPSS dapat dipaparkan Tabel 7 berikut.

Tabel 7. Model Summary

\begin{tabular}{|c|c|c|c|c|c|c|c|c|c|}
\hline \multirow[b]{2}{*}{ Model } & & \multirow[b]{2}{*}{$\begin{array}{c}\mathrm{R} \\
\text { Square }\end{array}$} & \multirow[b]{2}{*}{$\begin{array}{c}\text { Adjus } \\
\text { ted R } \\
\text { Squar } \\
\text { e }\end{array}$} & \multirow[b]{2}{*}{$\begin{array}{l}\text { Std. Error } \\
\text { of the } \\
\text { Estimate }\end{array}$} & \multicolumn{5}{|c|}{ Change Statistics } \\
\hline & & & & & $\begin{array}{c}\mathrm{R} \\
\text { Square } \\
\text { Chang } \\
\mathrm{e} \\
\end{array}$ & $\begin{array}{c}\mathrm{F} \\
\text { Change }\end{array}$ & df1 & df 2 & $\begin{array}{c}\text { Sig. F } \\
\text { Change }\end{array}$ \\
\hline 1 &, $820^{\mathrm{a}}$ & ,672 &, 631 & 7,86199 & 672 & 16,374 & 2 & 16 & 000 \\
\hline
\end{tabular}

a. Predictors: (Constant), komunikasi, keaktifan Untuk hasil output bagian pertama

Dari hasil output tabel di atas, maka besarnya hubungan antara keaktifan siswa dan komunikasi matematis terhadap prestasi belajar matematika yang dihitung dengan koefisien korelasi adalah 0,820, hal ini menunjukkan pengaruh yang kuat. Sedangkan kontribusi secara simultan variabel keaktifan siswa dan komunikasi matemati adalah $67,2 \%$, sedangkan $32,8 \%$ dipengaruhi oleh faktor lain.

Kemudian untuk mengetahu tingkat signifikasn koefisien korelasi ganda diuji secara keseluruhan. Hipotesis yang diajukan dalam hal ini adalah:

H0 : Keaktifan Siswa dan Komunikasi

Matematis tidak berhubungan secara simultan dan signifikan terhadap Prestasi Belajar Matematika

H1 : Keaktifan Siswa dan Komunikasi Matematis berhubungan secara simultan dan signifikan terhadap Prestasi Belajar Matematika

Berdasarkan tabel Model Summary diperoleh bahwa nilai probabilitas (sig. F change) $=0,000$. Karena nilai sig. $F$ change $0,000<0,05$, maka $\mathrm{H} 1$ diterima, artinya Keaktifan Siswa dan Komunikasi Matematis berhubungan secara simultan dan signifikan. Dan peneliti berlaku secara umum, tidak hanya pada sampel saja. 
KESIMPULAN DAN SARAN

Berdasarkan hasil penelitian dan pembahasan yang di paparkan di atas, maka dapat disimpulkan bahwa terdapat pengaruh yang signifikan keaktifan siswa terhadap prestasi belajar matematika. Dari ringkasan tabel ANOVA terlihat bahwa untuk taraf signifikansi sebesar $5 \%$ atau 0,05 diperoleh $\operatorname{sig}=0,000<$ 0,05. Dengan demikian, H0 ditolak dan H1 diterima, artinya terdapat pengaruh yang signifikan keaktifan siswa terhadap prestasi belajar matematika. Terdapat pengaruh yang signifikan komunikasi matematika terhadap prestasi belajar matematika. Dari ringkasan tabel ANOVA terlihat bahwa untuk taraf signifikansi sebesar 5\% atau 0,05 diperoleh sig $=0,005<0,05$. Dengan demikian, H0 ditolak dan $\mathrm{H} 1$ diterima, artinya terdapat pengaruh yang signifikan komunikasi matematis terhadap prestasi belajar matematika. Terdapat pengaruh yang signifikan keaktifan siswa dan komunikasi matematis terhadap prestasi belajar matematika. Dari ringkasan tabel SUMMARY terlihat bahwa untuk taraf signifikansi sebesar $5 \%$ atau 0,05 diperoleh $\operatorname{sig}=0,000<0,05$. Dengan demikian, H0 ditolak dan H1 diterima, artinya terdapat pengaruh yang signifikan keaktifan siswadan komunikasi matematis terhadap prestasi belajar matematika.
Diharapkan kepada peneliti selanjutnya untuk lebih menelititi secara mendalam mengenai keaktifan belajar siswa dan komunikasi matematis yang berpengaruh terhadap prestasi belajar matematika.Sehingga kemungkinan terbesar dengan adanya keaktifan belajar siswa, dan komunikasi matematis maka pretasi belajar matematika dapat meningkat.

\section{DAFTAR PUSTAKA}

Agustyaningrum, N. (2011).

Implementasi Model Pembelajaran

Learning Cycle 5E untuk Meningkatkan Kemampuan Komunikasi Matematis Siswa Kelas IX B SMP Negeri 2 Sleman.Seminar Nasional Matematika dan Pendidikan Matematika.ISBN : 978 - 979 $16353-6-3$.

Depdiknas.(2006). Kurikulum Tingkat

Satuan Pendidikan. Jakarta:

Departemen Pendidikan Nasional. (2008). Kurikulum Tingkat

Satuan Pendidikan. Jakarta:

Departemen Pendidikan Nasional. Imenda, Elsa. (2017). Meningkatkan Keaktifan Belajar Siswa dengan Menggunakan Model Project Bassed Learning di Kelas IV SDN 187/1 Muara Bulian. Jurnal Pendidikan dan Keguruan. 
Kusdiana, dkk. (2011). Peningkatan Aktivitas Siswa dalam Pembelajaran Ilmu Pengetahuan Sosial Menggunakan Metode Penugasan di Sekolah Dasar.

Marwodo. (2014). Strategi Sejarah dalam Meningkatkan Minat Belajar Siswa pada Mata Pelajaran Sejarah di SMAN 10 Pekanbaru. Jurnal IlmuIlmu Sejarah, Budaya dan Sosial.

Muhardi. (2004). Kontribusi Pendidikan dalam Meningkatkan Kualitas Bangsa Indonesia. Jurnal Karya Tulis Ilmiah. Volume XX No. 4 Oktober - Desember $2004: 478$ 492.

Nastitie, N. (2011). Prestasi Belajar Matematika dan Motivasi Mengerjakan Tugas Matematika pada Siswa SMP.Jurnal Pendidikan Matematika.

Purnama, L.I, dkk. (2016). Kemampuan Komunikasi Matematis Siswa Ditinjau Melalui Model Pembelajara Kooperatif Tipe Complete Sentence dan Team Quiz. Jurnal Pendidikan Matematika. Volume 10 No. 1.

Rahmawati, E. D. (2012). Penerapam Model Pembelajaran Kooperatif Tipr Group Investigatiom (GI) untuk Meningkatkan Keaktifan
Belajar dan Hasil Belajar Mata Pelajaran Sosiologi pada Siswa Kelas X 3 SMA Negeri Colomadu Tahun Pelajaran 2011/2012.Vol. 2 No. 1.

Siagian, Roida E. S. (2013).Pengaruh Minat dan Kebiasaan Belajar Siswa terhadap Prestasi Belajar Matematika. Jurnal Formatif. ISSN: 2088-351X.

Sulistyaningrum, C.A, dan Sumardi. (2013). Upaya Meningkatkan Keaktifan dan Hasil Belajat Siswa dalam Pembelajaran Matematika Melalui Strategi AktifCard Sort.Jurnal Pendidikan

Matematika.

Sugiyono. Metode Penelitian Pendidikan (Pendekatan Kuantitatif, Kualitatif, dan $R \& D)$. Alfabeta: Bandung, 2017.

Undang-Undang Republik Indonesia Nomor 20 Tahun 2003 Tentang Sistem Pendidikan Nasional. Jakarta: Departemen Nasional Republik Indonesia.

Zakiya, A., dkk.(2016).Penerapan Model Pembelajaran Berdasarkan Masalah untuk Meningkatkan Hasil Belajar Matematika Siswa Kelas VIII, SMPN 36 Pekanbaru. 